\title{
GERAKAN ORgANISASI KEMAHASISWAAN HIMPUNAN MAHASISWA ISLAM (HMI) Cabang Palembang 1998
}

\author{
${ }^{1}$ Lina Santiana, ${ }^{2}$ Endang Rochmiatun, ${ }^{3}$ Yazwardi \\ Fakultas Adab dan Humaniora UIN Raden Fatah Palembang \\ santianalina@gmail.com
}

\begin{abstract}
Abstrak. Penelitian ini menguji tentang gerakan organisasi kemahasiswaan Himpunan Mahasiswa Islam (HMI) Cabang Palembang 1998. Adapun yang menjadi fokus penelitian tesis ini adalah mengapa gerakan ini muncul, bagaimana gerakan ini berlangsung, kemudian dampak yang timbulkan. Dalam menjawab beberapa permasalahan ini dibutuhkan rekonstruksi peristiwa dengan menggunakan metode sejarah. Sumber-sumber penulisan yang digunakan berasal dari data primer dan sekunder. Adapun tulisan ini diulas dengan memperhatikan: pemilihan topik, pengambilan data sebagai sumber primer maupun sekunder, seleksi sumber berupa kritik data maupun kredibilitas sumber, kemudian dilengkapi dengan interpretasi, sehingga menampilkan pola dan corak gerakan HMI Cabang Palembang 1998 dalam bentuk penulisan yang diatur secara kronologis. Adapun jenis penelitian ini adalah jenis penelitian kualitatif, maka penelitian ini bersifat deskriptif-analitik. Berdasarkan kajian ini ditemukan bahwa, HMI Cabang Palembang 1998 memiliki kontribusi dalam gerakan aksi mahasiswa yang menuntut mundurnya presiden Soeharto. Gerakan-gerakan HMI Cabang Palembang 1998 yang pernah muncul sejauh ini sesungguhnya berperan sebagai inspirator dan katalisator yang kemudian menjadi penyebab jatuhnya sebuah rezim. Selain itu, gerakan HMI Cabang Palembang 1998 bukan sebagai gerakan politik murni melainkan hanya sebagai moral force dan agent of change.
\end{abstract}

Kata kunci: HMI, Reformasi, Reaksi HMI Cabang Palembang 1998.

\section{Pendahuluan}

Sebelum HMI berdiri pada 1947, di Indonesia sudah muncul berbagai organisasi Islam. Ada yang bergerak dibidang sosial-ekonomi, budaya, kemasyarakatan dan dibidang politik. Lahirnya organisasi Islam ini banyak dipengaruhi munculnya gerakan pembaruan di dunia Islam. Diantara organisasi itu adalah Serikat Dagang Islam (SDI), Jong Islamieten Bond (JIB/SIS), MIAI, dan Masyumi. Berdirinya SDI pada 1911, dipandang sebagai awal pergerakan Islam di Indonesia. SDI pada mulanya bergerak di lapangan sosial-ekonomi namun, setelah berubah menjadi Syarekat Islam

\footnotetext{
${ }^{1}$ Mahasiswa Program Magister (s2) Prodi Sejarah dan Kebudayaan Islam Fakultas Adab dan Humaniora UIN Raden Fatah Palembang.

${ }^{2}$ Dosen Program Magister (s2) Prodi Sejarah dan Kebudayaan Islam Fakultas Adab dan Humaniora UIN Raden Fatah Palembang.

${ }^{3}$ Dosen Program Magister (s2) Prodi Sejarah dan Kebudayaan Islam Fakultas Adab dan Humaniora UIN Raden Fatah Palembang.
} 
(SI), secara terang-terangan bergerak di lapangan politik radikal. ${ }^{4}$

Berdirinya SDI memberi pengaruh terhadap berdirinya organisasi Islam yang muncul kemudian. Pada 1912 di Yogyakarta berdiri Muhammadiya, Al-Irsyad pada 1923 di Bandung, NU di Surabaya pada 1926, Al-Wasliyah pada 1930 di Medan, di Majalengka berdiri PUI pada 1917, di Jakarta berdiri GPII pada 1945 dan PII pada $1947 .{ }^{5}$

Untuk itu, lahirlah pula gerakangerakan dan organisasi-organisasi yang mencoba untuk merefleksikan diri sebagai intelektual muslim seperti $\mathrm{HMI}^{6}$ yang merupakan salah satu organisasi yang lahir dari kancah perang dan revolusi. HMI lahir di tengah-tengah perjuangan bangsa yang sedang bergolak untuk mempertahankan kemerdekaan dari kekuasaan Belanda dan menegakkan kedaulatannya. ${ }^{7}$ Selain itu, kaum muslim juga merasa kesatuan umat sangat terancam, maka dirancang sebuah rencana untuk mendirikan HMI. ${ }^{8}$ Para pendiri organisasi mahasiswa ini meletakkan semangat dan tujuan yang jelas bagi HMI yaitu berjuang untuk mempertahankan Negara Republik Indonesia yang diproklamasikan 17 Agustus 1945. HMI juga bercita-cita untuk mempertinggi martabat bangsa serta ikut mengembangkan syiar agama Islam. ${ }^{9}$

${ }^{4}$ Abdurahman Wahid, Tjokroaminoto, Dawam Raharjo dan Hasan Hanafi, Islam, Sosialisme dan Kapitalisme, (Jakarta: Madani Press, 2000), hlm. 22-26.

${ }^{5} \mathrm{Ibid}$.

${ }^{6} \mathrm{HMI}$ akan dibahas lebih lanjut pada bab selanjutnya.

${ }^{7}$ Agussalim Sitompul, Sejarah Perjuangan HMI (Himpunan Mahasiswa Islam) 1947-1975, (Jakarta: Misaka Galiza, 2008), hlm. 5.

${ }^{8}$ Victor Tanja, HMI (Himpunan Mahasiswa Islam), Sejarah dan Kedudukannya di Tengah
Sepanjang sejarahnya, HMI memberi andil yang tidak kecil dalam perjuangan bangsa dan negara. Bahkan di masa perjuangannya, kader HMI ikut terjun ke dalam kancah perjuangan bersenjata melawan musuh, tanpa melupakan tugas pokoknya sebagai mahasiswa yang sedang menuntut ilmu. Di masa jayanya PKI, HMI telah berjuang habis-habisan untuk membendung dan melawan pengaruh ideologi komunis yang nyata-nyata bertentangan dengan Pancasila. ${ }^{10}$ Pada 1948, PKI melakukan pemberontakan di Madiun yang ketika itu seluruh bangsa Indonesia sedang menghadapi agresi Belanda. Penghianatan itu bertujuan untuk mengambil alih kekuasaan dari pemerintah yang sah dan memproklamasikan berdirinya Soviet Republik Indonesia. Kemudian pada 19 September 1948 Muso membentuk pemerintah front nasional. ${ }^{11}$

Pemberontakan itu membawa banyak korban, terutama dari kalangan umat Islam, kiai, guru, dari golongan nasional, para pejabat sipil dan militer. Menghadapi pemberontakan tersebut, PB HMI yang dipimpin wakil ketua Achmad Tirtosudiro, menggalang seluruh kekuatan mahasiswa dengan membentuk Corps Mahasiswa (CM). Hartono bertindak sebagai komandan, Achmad Tirtosudiro sebagai wakil komandannya yang juga merangkap sebagai ketua PPMI, menggantikan

Gerakan-gerakan Muslim Pembaharuan di Indonesia, (Jakarta: Sinar Harapan, 1991), hlm. 52.

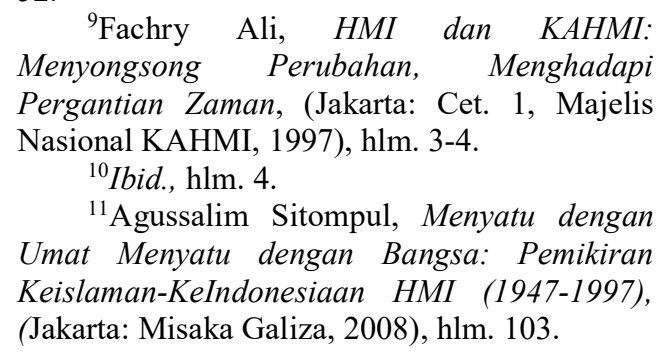

${ }^{11}$ Agussalim Sitompul, Menyatu dengan Umat Menyatu dengan Bangsa: Pemikiran Keislaman-KeIndonesiaan HMI (1947-1997), (Jakarta: Misaka Galiza, 2008), hlm. 103. 
Suripno yang terlibat dalam pemberontakan PKI. Gerakan anggotaanggota HMI berada di bawah koordinasi $\mathrm{CM}$, terjun ke daerah-daerah untuk membantu pemerintah menumpas pemberontakan PKI. CM juga dikerahkan untuk menghadapi dan mengusir penjajah. Selama masa-masa kritis itu, anggota-anggota HMI sementara meninggalkan bangku kuliah, mengganti pena menjadi senjata bambu runcing. ${ }^{12}$

Pergerakan untuk menumpas PKI terus dilakukan oleh mahasiswa di Yogyakarta, Jakarta dan Bandung serta beberapa daerah lainnya, pada titik puncaknya ketika KAMI melontarkan wacana "TRITURA" pada 10 Januari 1966. Tiga tuntutan tersebut berisi pembubaran PKI, pengaturan kembali kabinet dari unsur PKI, dan turunkan harga pokok. ${ }^{13}$ Para mahasiswa menuju sekretariat negara untuk menyampaikan aspirasi tersebut. Di kawasan ibukota lain juga terdapat aksi-aksi solidaritas dengan menduduki lokasi strategis. Aksi ini terus berlangsung sampai terjadinya pemogokan kuliah oleh para mahasiswa. Unjuk rasa semakin menyebar dengan rasa solidaritas diikuti para mahasiswa di Bandung. Tembok-tembok bangunan ibu kota dicoret tulisan Tritura sebagai bentuk ekspresi kekecewaan terhadap pemerintah. Sayangnya aspirasi tersebut tidak dipenuhi oleh Soekarno dan malah membentuk kabinet baru hingga terjadilah aksi besar-besaran dikalangan mahasiswa hingga tumbanglah rezim Soekarno.

\footnotetext{
${ }^{12}$ Agussalim Sitompul, Menyatu dengan Umat Menyatu dengan Bangsa: Pemikiran Keislaman-KeIndonesiaan HMI (1947-1997), hlm. 104.

${ }^{13}$ Francois Raillon, Politik dan Ideology Mahasiswa Indonesia: Pembentukan dan Konsolidasi Orde Baru 1966-1974, (Jakarta: LP3ES, 1989), hlm. 8.
}

\begin{tabular}{lcr}
\multicolumn{2}{c}{ Memasuki orde baru setelah } \\
tumbangnya rezim orde lama, \\
mahasiswa bungkam
\end{tabular} diberlakukannya NKK/BKK. Kebijakan NKK/BKK tidak muncul tiba-tiba. Peristiwa panjang yang penuh dinamika menjadi pemicu, terutama setelah mahasiswa dibantu militer berhasil menumbangkan Orde Lama pimpinan Presiden Soekarno. Organisasi seperti HMI dan GMNI tubuh subur. Hal ini menjadikan kritik terhadap pemerintah oleh mahasiswa ikut subur, melalui berbagai aksi unjuk rasa. Seperti pada protes mahasiswa terhadap dominasi modal asing di Indonesia pada 15 Januari 1974.

Kebijakan NKK/BKK berlaku resmi setelah Mendikbud Daoed Joedoef mengeluarkan Surat Keputusan Nomor. 0157/U/1978 tentang Normalisasi Kehidupan Kampus. Hal ini menyebabkan kehidupan kampus "Sterill" dari aktivitas politik. Dengan SK itu, mahasiswa tidak boleh melakukan kegiatan bernuansa politik. Jika melanggar, sanksi keras berupa pemecatan sudah disiapkan oleh Birokrasi Kampus, yang juga ditekan pemerintah. Kebijakan itu-pun disertai pembubaran Senat Mahasiswa dan Dewan Mahasiswa ditiap perguruan tinggi. Ini ditandai dengan Surat Keputusan Nomor 037/U/1979 tentang Badan Koordinasi Kemahasiswaan yang berhasil menghilangkan aktivitas politik dan organisasi mahasiswa di kampus. ${ }^{14}$ Akibat kebijakan itu, banyak mahasiswa

\footnotetext{
${ }^{14}$ Bayu Galih, Daoed Joesoef, "Kontroversi NKK/BKK, dan Beda Pendapatnya dengan Soeharto", Kompas.com, edisi Senin, 8 Agustus 2016. Tersedia: https://nasional.kompas.com, (8 Agustus 2016).
} 
yang memberontak dan tertangkap serta dicurigai. ${ }^{15}$

Pada tahap selanjutnya, dengan ditetapkannya RUU No. 8 pada 17 Juni 1985, tentang Pancasila sebagai satusatunya asas organisasi. HMI masih bersikukuh agar penerimaan asas tunggal Pancasila dimusyawarahkan terlebih dahulu dalam forum kongres. Maka muncul-lah pro dan kontra di kalangan HMI tentang kewajiban menerapkan asas Pancasila sebagai asas organisasi. Karena konsep Presiden Soekarno tentang asas tunggal Pancasila akhirnya berdampak pada terpecahnya HMI menjadi dua kubu. Kubu pertama dinamakan HMI MPO (Majelis Penyelamat Organisasi), yang menolak Pancasila sebagai asasnya. Kedua, HMI Diponegoro (HMI DIPO) yang menerima Pancasila sebagai asasnya. ${ }^{16}$ Peristiwa di atas menjadi hal yang sangat penting pada periode 1986 di kepengurusan HMI Cabang Palembang karena, pada periode itu berpihaknya HMI Cabang Palembang kepada pemerintah dengan menerima asas Pancasila, dan bergabung di HMI DIPO. ${ }^{17}$

Melihat pergerakan HMI dibeberapa daerah seperti di Yogyakarta dan Jakarta pada masa orde baru yang begitu banyak terlibat dalam pergolakan politik pemerintah yang berujung pada tuntutan reformasi total, karena rasa ketidak puasan atas kebijakan pemerintah. Oleh karena itu, penting untuk mengamati seberapa besar gerakan organisasi kemahasiswaan HMI

\footnotetext{
${ }^{15}$ Wawancara dengan Umar Husen (Ketua Umum HMI Cabang Palembang Periode 19851986), pada Selasa, 29 Mei 2018 di Palembang.

${ }^{16}$ Ahmad Syafi"i Safinuddin, HMI dan Wacana Revolusi Sosial, (Jakarta: Hijau Hitam, 2003), hlm. 66.
}

di beberapa daerah lainnya pada periode 1998 khususnya di Palembang. Mengingat bahwa, pada periode tersebut telah terjadi pergolakan cukup besar antara pemerintah dan mahasiswa.

\section{Metode}

Penelitian ini termasuk jenis penelitian kualitatif. Karena penelitian ini merupakan jenis penelitian kualitatif, maka penelitian ini bersifat deskriptifanalitik. Adapun teknik analisis data dalam penelitian ini diuraikan dengan metode penelitian sejarah dalam beberapa tahap yang dimulai dari pengambilan data (heuristik), kritik sumber (verifikasi), interpretasi dan penulisan (historiografi). ${ }^{18}$ Adapun sumber data yang di tulis terbagi dalam dua kelompok yaitu, sumber primer dan sumber sekunder. Sedangkan teknik pengumpulan data yang dilakukan oleh peneliti adalah triangulasi. Triangulasi diartikan sebagai teknik pengumpulan data yang bersifat menggabungkan dari berbagai teknik pengumpulan data dan sumber data yang telah ada. ${ }^{19}$

\section{Hasil Penelitian}

\section{Jalannya Aksi Mahasiswa}

Memasuki 1998, bangsa Indonesia dihadapkan pada berbagai permasalahan. Krisis moneter yang muncul sejak pertengahan 1997 telah merusak sendi-sendi ekonomi nasional. Lemahnya fundamen ekonomi pada akhirnya berpengaruh pula pada sektor kehidupan lain secara luas. Tidak heran dibeberapa daerah banyak ditemukan

\footnotetext{
${ }^{17}$ Wawancara dengan Umar Husen (Ketua Umum HMI Cabang Palembang Periode 19851986), pada Selasa, 29 Mei 2018 di Palembang.

${ }^{18}$ Kuntowijoyo, Pengantar Ilmu Sejarah, (Yogyakarta: Bentang Pustaka, 2005), hlm. 90.

${ }^{19}$ Sugiyono, Metode Penelitian Kuantitatif, Kualitatif, dan R\&D, hlm. 205.
} 
antrian panjang rakyat yang hendak membeli kebutuhan pokok beras, gula, minyak goreng, dan BBM. ${ }^{20}$

Ekses lebih jauh masyarakat mulai resah dan takut pada kenyataan yang akan menimpa mereka. Kecemasan masyarakat itu akhirnya terefleksi dalam aksi-aksi unjuk rasa, terutama yang dimotori oleh mahasiswa. Aksi-aksi mahasiswa tersebut terus berlangsung seiring memuncaknya suhu politik 1998 yang dipicu oleh tertembaknya mahasiswa Universitas Trisakti hingga berujung pada tuntutan turunnya Presiden Soeharto. ${ }^{21}$ Elemen-elemen mahasiswa yang bernaung di bawah bendera organisasi mehasiswa di berbagai Universitas melakukan unjuk rasa akbar di gedung DPR/MPR RI. ${ }^{22}$

Ribuan mahasiswa di Palembang pun melakukan long marc ke kantor DPRD. ${ }^{23}$ Di halaman gedung DPRD Sumsel, mahasiswa membacakan tuntutan yang antara lain berisi: Segera laksanakan sidang istimewa. Cabut undang-undang yang tidak relevan lagi dengan kehidupan berbangsa dan bernegara. Usut dan hentikan penculikan para aktivis penyuara kebenaran serta turunkan harga yang menyengsarakan rakyat (sembako-BBM- ongkostranfortasi, dll). ${ }^{24}$

Aksi yang telah berlangsung selama beberapa hari itu kemudian kembali digelar dengan diikuti oleh

\footnotetext{
${ }^{20}$ Wawancara dengan Akmal Hawi, (Pengurus HMI Cabang Priode 1981-1982), pada Rabu, 30 Mei 2018 di Palembang.

${ }^{21}$ Wawancara dengan Darul Qudni (Pengurus Cabang Periode 1977-1978), 10 Mei 2019, Palembang.

${ }^{22}$ Andik Matulessy, Mahasiswa dan Gerakan Sosial, (Surabaya: Srikandi, 2005), hlm. 14.
}

sekitar 5.000 mahasiswa dari berbagai perguruan tinggi Palembang yang berasal dari Unsri, IAIN Raden Fatah, UMP, STIE, STMIK Bina Darma, STKIP PGRI, STISIPOL, Unpal, Universitas IBA, Universitas Syakjakirti. Mahasiswa kembali melakukan long march $^{25}$ menuju ke gedung DPRD Sumsel di Jl. Kapten A rivai untuk menyampaikan sikap hingga memenuhi pelataran tangga utama gedung DPRD dengan meneriaknya yelyel menuntut segera dilakukannya reformasi. ${ }^{26}$

Dikawasan J1 Jend A Yani Plaju, aksi kekerasan tak terelakkan. Ini terjadi saat mahasiswa UMP dan STKIP PGRI, sekitar pukul 08.30 WIB, bersiap turun ke jalan. Mereka mendapat pengawalan ketat dari aparat keamanan. Menjelang keberangkatan, terjadi lemparan batu kearah mahasiswa. Akibatnya seorang mahasiswa STKIP, Hasanuddin menderita luka di bagian kening. Seorang petugas Bharatu Rudi Hartono (anggota Satpol Air) juga menderita luka. Keduanya lantas dirawat di RS PKU Muhammadiyah. ${ }^{27}$

Usai insiden itu, ribuan mahasiswa meneruskan long march, sehingga menyebabkan kemacetan di sepanjang Jl. Jenderal Sudirman. Sesampai di RS. Charitas, rombongan mahasiswa UMP dan STKIP PGRI ikut bergabung dengan ribuan mahasiswa IAIN Raden Fatah, Unanti, Universitas

\footnotetext{
23"Mahasiswa Kian Berang", Sumatera Ekspres, edisi Minggu, 3 Mei 1998, hlm. 2, Kolom. 3-4.

${ }^{24}$ Ibid., hlm. 2, Kolom. 4.

25" Aksi di Palembang, 45 Toko Hancur, 4 Mahasiswa Luka”, Sumatera Ekspres, edisi Kamis, 14 Mei 1998, hlm. 1-10, Kolom. 2-3.

${ }^{26}$ Ibid., hlm. 1. Kolom. 1-2.

${ }^{27}$ Ibid., hlm. 1, Kolom. 3.
} 
IBA, dan Unitas. Dengan beriringan ribuan mahasiswa ini menuju gedung DPRD Sumsel. Ketika tiba di depan bengkel dan Showroom Yamahaberdampingan dengan Pool Bus Damri terjadi pelemparan batu, sehingga kacakaca pecah. Petugas langsung melakukan tindakan pengamanan dan terus menggiring mahasiswa. ${ }^{28}$

Sekitar pukul 10.45 WIB, ratusan mahasiswa yang berada di depan gedung DPRD berusaha menerobos pagar betis aparat untuk memasuki gedung. Aksi dorong-dorongan pun terjadi. Dalam waktu singkat mahasiswa berhasil menerobos halaman DPRD Tk I Sumsel. Sebelumnya sekitar pukul 08.30 WIB sejumlah kecil mahasiswa duduk lesehan sembari mengibarkan spanduk di ruas Jl. POM IX Kampus. Ketika itu rombongan ini berusaha masuk ke halaman DPRD untuk menurunkan bendera yang ada di pelataran gedung menjadi setengah tiang, sebagai rasa berkabung atas tewasnya enam mahasiswa Universitas Trisakti sebelumnya. Meski sempat dicegah, tepat pada pukul 09.00 WIB petugas membiarkan mahasiswa menurunkan bendera menjadi setengah tiang. ${ }^{29}$

Setelah semakin siang suasana semakin ramai, ribuan mahasiswa menginginkan agar pimpinan dewan muncul di tengah-tengah mereka. Tetapi dewan malah menginginkan pertemuan melalui perwakilan. Sehingga diutuslah utusan dari perguruan tinggi Palembang seperti Arief Patra, Yenni Roslaini, Syafitri Irwan, lili, Edi Sutriono, dan Hasanuddin. Pertemuan itu diterima anggota dewan yang dipimpin oleh $\mathrm{H}$ Muchtar, Fakhrurozi Dahlan, Natsir Jakfar, (ketiganya Wakil Ketua), Nasrul

${ }^{28}$ Ibid., hlm 1. Kolom 4.

${ }^{29}$ Ibid., hlm. 1, Kolom. 5-6.
Madang (Ketua Komisi B), dan sejumlah anggota komisi lain seperti Benyamin Lani, Darwin CU, dan Azhari. Di hadapan dewan, utusan mahasiswa menyampaikan pernyataan sikap yang bertajuk "Deklarasi Gotong Royong 1998". ${ }^{30}$

Usai pertemuan itu, seluruh utusan kembali bergabung dengan ribuan mahasiswa lainnya. Pukul 13.00 WIB lebih, ribuan mahasiswa itu meninggalkan gedung DPRD. Di seperempat J1 Kapten A. Rivai (Simpang Kampus) ribuan mahasiswa itu terpecah. Ratusan diantaranya menuju ke kantor Gubernur. Sebagian besar lainnya menuju ke kawasan IP, sebagian kecil lainnya kembali ke kampus. Dalam perjalanan ke IP kerusuhan terjadi. Puluhan kaca rumah dan toko (ruko) di sepanjang Jl. Radial dan Jl. Letkol Iskandar pecah terkena lemparan batu dan benda-benda keras lainnya. Selain ruko enam mobil juga terkena lemparan batu sehingga kaca-kacanya pecah. Untuk menghindari lemparan batu ini di sekitar Jl. Radial dan Jl. Letkol Iskandar, sebagian pemilik toko langsung memasang sajadah dan karton bertuliskan "Muslim" dan "Muhammadiyah" di depan toko masing-masing. Ini dimaksudkan agar toko-toko mereka terhindar dari lemparan batu. ${ }^{31}$

Petugas keamanan pun akhirnya menembahkan peluru karet kepada mahasiswa. Selain itu petugas juga menyemprotkan air berwarna kuning, juga menggunakan pentungan serta peralatan kayu untuk membubarkan pelaku kerusuhan tersebut. Selama membubarkan mahasiswa unjuk rasa tersebut, dua mahasiswa IAIN Raden
${ }^{30} \mathrm{Ibid}$., hlm. 1, Kolom. 7-8.

${ }^{31} \mathrm{Ibid}$., hlm. 1. Kolom. 8. 
Fatah mengalami luka-luka di bagian kepala akibat pukulan oleh petugas. Sementara seorang petugas mengalami luka terbuka di pelipis kiri akibat lemparan batu. ${ }^{32}$

Upaya-upaya unjuk rasa dan dialong terus dilakukan oleh mahasiswa. Seperti pada 15 Mei 1998, HMI cabang Palembang bersama sedikitnya 80 pemuda hadir dalam acara dialog bersama unsur Muspida Kotamadya Palembang di ruang sidang utama gedung DPRD Kotamadya Palembang. Dialong itu dihadiri dari berbagai unsur pemuda, seperti dari mahasiswa STISIPOL Candradimuka, Gema Kosgoro, Mahasiswa Pancasila, Unpal, Pemuda Muhammadiyah, dan unsur KNPI kotamadya Palembang. ${ }^{33}$

Dialog yang dipimpin oleh ketua KNPI kotamadya Palembang ini berjalan dengan terbuka. Dalam pembahasan masalah reformasi, menurut mereka tiga bidang utama yang harus direformasi adalah masalah ekonomi, hukum, dan politik. Ketiga bidang ini harus dilakukan reformasi secara total. Dalam kesempatan dialog pun menghasilkan kesimpulan bahwa mendukung aksi mahasiswa untuk reformasi total, turunkan harga sembako dan BBM, petugas keamanan harus bertindak arif dan bijaksana terhadap gerakan mahasiswa, usut tuntas kematian mahasiswa universitas trisakti. ${ }^{34}$

Pada Rabu 20 Mei 1998, di halaman DPRD TK I Sumsel, Jl. POM IX, sebanyak 2.000-an mahasiswa dari 27 perguruan tinggi di Kota Palembang

${ }^{32}$ Ibid., hlm. 1. Kolom. 10-11.

33"'Pemuda dan Muspida Berdialog", Sriwijaya Post, edisi Jumat, 15 Mei 1998.

${ }^{34}$ Ibid. menduduki DPRD TK I Sumsel sekitar lima jam. Penjagaan ketat disekitar DPRD tidak menghalangi mahasiswa untuk mendatangi kantor DPRD Sumsel. Mahasiswa berdatangan ke gedung wakil rakyat ini secara bergelombang menggunakan bus kampus. Gedung DPRD dipenuhi warna biru tua, biru muda, orange, ungu, coklat susu, coklat tua, hijau dan kuning. Sebelum memulai aksinya para mahasiswa mendaulat semua anggota dewan untuk turun menghadiri orasi yang mereka gelar. Pada kesempatan itu HM Arub SH dan ketiga wakil ketua DPRD Sumsel F Rozi Dhalan SH, H Mukhtar dan M Natsir DJakfar bahkan ikut lesehan di aspal di pelataran DPRD Sumsel. ${ }^{35}$

Dalam rangkaian aksi itu dimulai dengan menurunkan bendera merah putih di halaman DPRD Sumsel yang semula dikibarkan penuh menjadi hanya setengah tiang sebagai tanda duka atas gugurnya para pejuang reformasi. Penurunan bendera oleh mahasiswa itu diiringi lagu kebangsaan Indonesia raya. Acara dilanjutkan dengan mengheningkan cipta. ${ }^{36}$

Aksi unjuk rasa ini pun berjalan tertib dengan menggelar aksi mimbar bebas dari perwakilan masing-masing mahasiswa. Tuntutan yang dikemukakan kali ini senada yaitu menginginkan agara Soeharto mundur dari jabatannya. Mahasiswa juga menggelar spanduk dan poster-poster besar yang dipajang di balkon gedung DPRD. ${ }^{37}$ Isi poster antara lain, "DPR Mana Janjimu, Percepat Sidang Istimewa dan Demokrasi Mati, Rakyat Lapar". ${ }^{38}$ Poster lainnya

35"Arub Dipaksa Teken Deklarasi", Sriwijaya Post, edisi Kamis, 21 Mei, 1998, hlm. 2. Kolom. 1-2.

${ }^{36}$ Ibid.. hlm. 2. Kolom. 2.

${ }^{37}$ Ibid.

${ }^{38}$ Ibid. 
ditemple di dinding atas gedung DPRD. Bunyinya, "Jangan Tunggu Korban Berikutnya, Segera! Lakukan SI MPR Munuju Reformasi, Kembalikan Kedaulatan Rakyat, Pulanglah ke Jalan Yang Benar Pak Tua, Mana Janjimu Harmoko, Dengar Jeritan Wong Cilik." 39

Selain mahasiswa, yang turut berorasi adalah dosen dari beberapa universitas. Pada kesempatan itu juga digelar drama parody tentang pernyataan politik ketua DPR Harmoko agar presiden Soeharto mengundurkan diri dan pernyataan Presiden tentang desakan agar dirinya mundur. Para mahasiswa memerankan tokoh Harmoko, Amien Rais, Presiden Soeharto, Kiai dan Mbak Tutut. ${ }^{40}$

HM Arub yang untuk pertama kali tampil di hadapan mahasiswa sejak maraknya aksi sepekan itu, terlihat santai dan berdialong dengan mahasiswa. Pada aksi mimbar bebas tersebut, sempat pula dibacakan sumpah mahasiswa yang isinya sama dengan sumpah pemuda. "Kami Mahasiswa dan Mahasiswi Indonesia Mengaku Bertanah Air Satu, Tanah Air Tanpa Penindasan. Berbangsa Satu, Bangsa yang Gandrung Keadilan, dan Berbahasa Satu Bahasa Kemenangan". ${ }^{41}$

Pada puncak acara para mahasiswa membuat deklarasi atau surat pernyataan kebulatan tekad. Isinya menuntut presiden Soeharto agar mundur dari jabatan presidennya. Turut menandatangani HM Arub SH dan para pimpinan DPRD lainnya. Ketua DPRD diminta menandatangani sebagai pihak yang mengetahui. Kemudian mahasiswa

\footnotetext{
${ }^{39}$ Ibid.

${ }^{40}$ Ibid.

${ }^{41}$ Ibid.

${ }^{42}$ Ibid., hlm. 2. Kolom. 1.
}

minta agara surat itu distempel DPRD Sumsel dan dikirim melalui Faksimile ke DPR RI. ${ }^{42}$

Hal lain yang dilakukan oleh HMI Cabang Palembang 1998 adalah menolak Dwifungsi ABRI. Dwifungsi ABRI adalah suatu doktrin di lingkungan militer Indonesia yang menyebut bahwa TNI memiliki dua tugas yaitu pertama menjaga keamanan dan ketertiban Negara dan kedua memegang kekuasaan dan mengatur Negara. Dengan peran ganda ini, militer diizinkan untuk memegang posisi di dalam pemerintahan. Pengaturan Dwifungsi ABRI ini dalam Undang-Undang baru dimulai pada era Orde Baru, UU yang mengatur Dwifungsi ABRI ini ialah ketetapan No. XXIV/MPRS/1966 yang kemudian disusul oleh UU No. 15/1969 tentang pemilihan umum dan UU No. 16/1969, ketetapan MPR No. IV/MPR/1978 tentang ketentuanketentuan pokok pertahanan keamanan Negara, dan UU No. 2/1988 tentang Prajurit ABRI. ${ }^{43}$

Dampak dwifungsi ABRI ini menyebabkan banyaknya jabatan pemerintah mulai dari Bupati, Walikota, Gubernur, Pejabar Eselon, Menteri, bahkan Duta Besar di isi oleh anggota ABRI yang "dikaryakan". Selain dilakukannya pembentukan Fraksi ABRI di Parlemen, ABRI bersama-sama KORPRI pada waktu itu juga dijadikan sebagai salah satu tulang punggung yang menyangga keberadaan Golkar sebagai partai politik yang berkuasa pada saat itu. ABRI melalui berbagai yayasan yang dibentuk diperkenankan mempunyai dan

\footnotetext{
${ }^{43}$ Welli Putra, Dwifungsi ABRI, Kompasiana.com, 21 Desember 2012. Tersedia: www. Kompasiana.com, 21 Desember 2012.
} 
menjalankan berbagai bidang usaha dan lain sebagainya. ${ }^{44}$

HMI Cabang Palembang kemudian melakukan pengembangan opini ABRI harus kembali ke barak dan pencabutan Dwifungsi ABRI harus segera dilakukan, karena Dwifungsi ABRI ini menimbulkan kencenderungan ABRI untuk bertindak represif dan tidak demokratis/otoriter. Selain itu, ABRI dengan bebas bergerak untuk menjabat di pemerintah, sehingga tidak berjalannya fungsi kontrol oleh Parlemen. Dampaknya adalah terjadinya penyalahgunaan kekuasaan, misalnya dalam bentuk korupsi. Hal ini dapat terjadi karena ABRI juga yang bertindak sebagai parlemen sehingga ia tidak ingin repot-repot melakukan kontrol terhadap bawahannya. ${ }^{45}$

\section{Gerakan Organisasi Kemahasiswaan: HMI Cabang Palembang 1998}

Kondisi kebijakan politik pemerintahan yang dianggap tidak adil, menindas dan tak bisa ditolerir telah menjadi sumber utama munculnya gerakan organisasi kemahasiswaan Himpunan Mahasiswa Islam (HMI) Cabang Palembang 1998, meskipun di dalamnya juga sudah muncul aksi-aksi kolektif mahasiswa lainnya.

Bila melihat ciri gerakan sosial model Rajendra Singh, peran ideologi, kepemimpinan, strategi, komunikasi, mobilisasi bisa turut membentuk aspekaspek kontigen dari sebuah gerakan

\footnotetext{
${ }^{44}$ Wawancara dengan Alwi Suryono (Pengurus HMI Cabang Palembang Periode 1997-1998), Sabtu, 4 Agustus 2018, Palembang.

${ }^{45}$ Wawancara dengan Darul Qudni (Pengurus Cabang Periode 1977-1978), 10 Mei 2019, Palembang.
}

sosial. ${ }^{46}$ Faktor utama untuk memobilisasi massa dalam gerakan ini dicirikan oleh adanya suatu ideologi yang sama-sama dianut oleh partisipannya. Dalam totalitas gerakannya HMI Cabang Palembang menjadikan Islam sebagai sumber nilai. Motivasi dan inspirasi gerakan HMI cabang Palembang bersumber dari adanya kesadaran kolektif anggota sebagai organisasi mahasiswa yang mempunyai peran vital sebagai agent of change, ${ }^{47}$ yang kemudian membuka ruang untuk sama-sama melakukan sebuah gerakan perlawanan terhadap pemerintah.

Adapun suatu struktur organisasi dengan sistem kepemimpinan ikut membentuk gerakan sosial HMI cabang Palembang 1998. Pada masa ini HMI cabang Palembang masih dipimpin oleh Edi Sutriyono sebagai Ketua Umum HMI Cabang Palembang periode 19971998. Dalam hal ini, pemimpin bertugas sebagai penggerak anggota-anggotanya (Partisipan-partisipannya) untuk melakukan sebuah mobilisasi. Dalam penelitian ini juga ditemukan bahwa, strategi yang dijalankan HMI Cabang Palembang 1998 untuk mencapai tujuannya adalah melakukan konsolidasi dengan organisasi-organisasi lain dalam setiap aksi sosial yang dilakukan. Karena elemen yang dilibatkan dalam aksi sosial itu adalah mahasiswa, tak jarang HMI Cabang Palembang dalam gerakannya melibatkan lembaga kampus lewat Senat Mahasiswa yang kebetulan terdapat kader HMI. Selain itu, HMI Cabang Palembang 1998 juga

\footnotetext{
${ }^{46}$ Rajendra Singht, Gerakan Sosial Baru, hlm. 41.

${ }^{47}$ Wawancara dengan Hendri Zainuddin (Pengurus HMI Cabang Palembang periode 1997-1998), pada Rabu,16 Mei 2018 di Palembang.
} 
berkonsolidasi dengan OKP, Ormas, serta Elemen lainnya dalam menyikap tuntutan reformasi. ${ }^{48}$

Kemudian dalam aksi dan dialog yang dilakukan, HMI cabang Palembang 1998 membangun komunikasi yang jelas yakni; mendesak negara untuk segera melakukan solusi untuk menurunkan harga, segera lakukan SI MPR/DPR, bentuk pemerintah koalisi, selenggarakan pemilu ulang, akuntabilitas publik terhadap kekayaan konglomerat dan pejabat negara, dan redefinisi Dwifungsi ABRI. ${ }^{49}$ Selain itu HMI Cabang Palembang juga menuntut penghapusan legalitas perjudian serta penghapusan KKN di Sumsel. Akhirnya, dampak dari mobilisasi gerakan yang dilakukan ditandai dengan runtuhnya sebuah rezim orde baru yakni mundurnya presiden Soeharto dari jabatan ke presidenan.

Karenanya, untuk sampai pada gerakan sosial ini, masing-masing aspek di atas memberi kontribusi penting dan nyata dalam perubahan identitas perjuangan. Ini terlihat pada elemen dasar gerakan HMI Cabang Palembang 1998 yang bersumber dari kenyataan ketidakadilan, lemahnya fundamental ekonomi, dan sistem pemerintahan yang diktator.

Bila ditelusuri lebih jauh, persoalan yang diperjuangkan HMI Cabang Palembang 1998 tidak hanya mempersoalkan masalah politik, namun menyangkut pula mengkritisi persoalan sosial. Namun demikian, bila diamati gerakan HMI Cabang Palembang 1998

\footnotetext{
${ }^{48}$ Wawancara dengan Alwi Suryono, (Pengurus HMI Cabang Palembang Periode 1997-1998), Sabtu, 4 Agustus 2018, Palembang.

${ }^{49} \mathrm{Ibid}$.

${ }^{50}$ Wawancara dengan Hendri Zainuddin (Pengurus HMI Cabang Palembang periode
}

ini dalam menuntut reformasi hanyalah sebatas penguatan atas gerakan yang telah dilakukan oleh Pengurus Besar HMI di pusat. Hal ini dikarenakan, pada waktu itu PB HMI membuat semacam kerangka acuan untuk gerakan aksi nasional HMI se-Indonesia. Sehingga isu yang dibangun atau yang dimunculkan baik dari pusat sampai ke daerah semuanya sama yaitu menuntut reformasi. ${ }^{50}$

Meski demikian, gerakan yang dilakukan HMI Cabang Palembang 1998 ini juga lahir dari kesadaran untuk sebuah perubahan terhadap segala tatanan yang dianggap tidak sesuai di Sumsel. HMI cabang Palembang bertindak dan melakukan kritik terhadap kebijakan pemerintah terhadap maraknya Kolusi, Korupsi dan Nepotisme (KKN) di Sumsel akibat kurangnya daya kontrol pemerintah pusat terhadap pemerintah daerah. ${ }^{51}$

Dengan demikian, HMI Cabang Palembang 1998 menghendaki agar reformasi dilaksanakan secara menyeluruh dari pusat sampai ke daerah tak terkecuali di Sumsel. Pada proses ini yang terjadi adalah suatu gerakan sosial sebagai bentuk perlawanan terhadap dominasi kekuasaan pemerintah. Diakui ataupun tidak, pada peristiwa reformasi HMI Cabang Palembang 1998 sesungguhnya telah ikut berperan sebagai inspirator dan katalisator yang kemudian menjadi penyebab jatuhnya sebuah rezim.

Berbagai persoalan yang memunculkan protes di kalangan

\footnotetext{
1997-1998), pada Rabu,16 Mei 2018 di Palembang.

${ }^{51}$ Wawancara dengan Hendri Zainuddin (Pengurus HMI Cabang Palembang periode 1997-1998), pada Rabu,16 Mei 2018 di Palembang.
} 
mahasiswa tersebut di atas sesuai dengan pandangan Rajendra Singh, bahwa gerakan sosial dicirikan oleh adanya kesadaran kolektif yang bangkit dari dalam diri masyarakat terhadap beberapa nilai, norma, dan praktek sosial di sebuah masyarakat pada periode tertentu yang dianggap tak adil, menindas dan tak bisa ditolerir oleh sebuah kelompok sosial. ${ }^{52}$ Disebutkan pula oleh Singh, bahwa gerakan sosial merujuk pada sebuah teknik sosial yang alami, yang sering kali terpaksa menentang dan menolak situasi-situasi ketidakadilan dan penindasan yang ada. Aksi-aksi dan gerakan-gerakan sosial merupakan aksi sosial yang disengaja yang memiliki tujuan, metode, dan prosedur organisasi serta komunikasi tertentu. ${ }^{53}$

\section{Kesimpulan}

Penelitian ini menyimpulkan bawah gerakan-gerakan HMI Cabang Palembang 1998 yang pernah muncul sejauh ini sesungguhnya telah ikut berperan sebagai inspirator dan katalisator yang kemudian menjadi penyebab jatuhnya sebuah rezim. Lebih dari itu HMI Cabang Palembang sepanjang 1998 telah memainkan perannya sebagai the moral force dan agent of social change.

Gerakan HMI Cabang Palembang 1998 dalam studi ini secara khusus menunjuk pada "Gerakan organisasi kemahasiswaan" yakni sebagai gerakan sosial. Gerakan utama yang diperjuangkan adalah nilai-nilai atau sistem nilai yang sifatnya adalah universal: seperti keadaan sosial, kebebasan, kemanusiaan, demokrasi dan konsolidasi kepada rakyat yang tertindas.

\footnotetext{
hlm. 39 .
}

${ }^{52}$ Rajendra Singh, Gerakan Sosial Baru,

\section{Daftar Pustaka}

Abdurahman Wahid, Tjokroaminoto, Dawam Raharjo dan Hasan Hanafi, (2000). Islam, Sosialisme dan Kapitalisme. Jakarta: Madani Press.

Ali, Fachry. (1997). HMI Dan KAHMI Menyongsong Perubahan. Menghadapi Pergantian Zaman. Cet. 1. Jakarta: Majelis Nasional KAHMI.

Basrowi dan Sukidin. (2003). TeoriTeori Perlawanan dan Kekeraasan Kolektif. Surabaya: Insan Cendikia.

Bayu Galih, Daoed Joesoef, "Kontroversi NKK/BKK, dan Beda Pendapatnya dengan Soeharto". Kompas.com. edisi Senin. 8 Agustus 2016. Tersedia: https://nasional.kompas.com. (8 Agustus 2016).

Harahap. Muchtar E. (1993). Mahasiswa dalam Politik. Jakarta: NSEAS.

Idil Akbar. (2016). Demokrasi dan Gerakan Sosial (Bagaimana Gerakan Mahasiswa Terhadap Dinamika Perubahan Sosial). Jurnal Wacana Politik. Vol. 1, No. 2.

J. Moleong, Lexy. (2009). Metode Penelitian Kualitatif. Bandung: Remaja Rosda Karya.

Kuntowijoyo. (1995). Pengantar Ilmu Sejarah. Yogyakarta: Bentang Budaya.

\footnotetext{
${ }^{53}$ Ibid., hlm. 40.
} 
76 Lina Santiana, et all.

Matulessy, Andik.( 2005). Mahasiswa Dan Gerakan Sosial. Surabaya: Srikandi.

Raillon, Francois. (1985). Politik dan Ideology Mahasiswa Indonesia Pembentukan Konsolidasi Orde Baru 1966-1974. diterjemahkan oleh Nasir Tamara. Jakarta: LP3ES.

Sitompul, Agussalim. (2008). Menyatu dengan Umat Menyatu dengan Bangsa Pemikiran KeIslaman dan KeIndonesiaan HMI (1947-1997). Jakarta: Misaka Galiza. (2008). Sejarah Perjuangan Himpunan Mahasiswa Islam (19471975). Jakarta: Misaka Galiza.

Singh, Rajendra. (2010). Gerakan Sosial Baru. Terj. Eko P. Darmawan. Yogyakarta: Resist Book

Sugiyono. (2002). Metode Penelitian Kuantitatif, Kualitatif, dan $R \& D$. Bandung: Alfabeta. Cet ke-16.

Syafi"I Safinuddin, Ahmad. (2003). HMI dan Wacana Revolusi Sosial. Jakarta: Hijau Hitam.

Tanja, Victor. (1991). Himpunan Mahasiswa Islam Sejarah dan Kedudukannya di tengah GerakanGerakan Muslim Pembaharuan di Indonesia. Jakarta: Pustaka Sinar Harapan. Cet. 2.

Wawancara dengan Umar Husen (Ketua Umum HMI Cabang Palembang Periode 1985-1986). Pada Selasa, 29 Mei 2018 di Palembang.

"Mahasiswa Kian Berang". Sumatera Ekspres. Edisi Minggu, 3 Mei 1998.

"Aksi di Palembang, 45 Toko Hancur, 4 Mahasiswa Luka". Sumatera Ekspres. Edisi Kamis, 14 Mei 1998.
"Pemuda dan Muspida Berdialog". Sriwijaya Post. Edisi Jumat, 15 Mei 1998.

"Arub Dipaksa Teken Deklarasi". Sriwijaya Post. Edisi Kamis, 21 Mei, 1998.

Welli Putra. Dwifungsi ABRI. Kompasiana.com. 21 Desember 2012. Tersedia: $w w w$. Kompasiana.com. 21 Desember 2012.

"Mahasiswa Tuntut Reformasi di Sumsel". Sriwijaya Post. Edisi Selasa, 26 Mei 1998.

Wawancara dengan Alwi Suryono, (Pengurus HMI Cabang Palembang Periode 1997-1998). Pada Sabtu, 4 Agustus 2018 di Palembang.

Wawancara dengan Hendri Zainuddin, (Ketua Bidang Komunikasi Umat HMI Caban Palembang periode 1997-1998). Pada Rabu, 16 Mei 2018 di Palembang.

Wawancara dengan Akmal Hawi. (Pengurus HMI Cabang Priode 19811982). Pada Rabu, 30 Mei 2018 di Palembang.

Wawancara dengan Darul Qudni (Pengurus Cabang Periode 19771978). Pada Kamis, 10 Mei 2018, Palembang. 